\section{To translate pharmacogenetics in geriatrics: towards a personalized medicine}

\author{
Davide Seripa, Giulia Paroni, \\ Michele Lauriola, Antonio Greco
}

Geriatric Unit and Gerontology, Geriatrics Research Laboratory, Department of Medical Sciences, IRCCS Casa Sollievo della Sofferenza, San Giovanni Rotondo (FG), Italy

\section{Abstract}

Geriatric wards represented a very interesting clinical setting in which an increased drugs use rise the prevalence of adverse drug reactions (ADRs) and therapeutic failures (TFs). These are not independent phenomena, but the severe counterposed manifestations of a continuum of phenotypes in which the better drug response is the midpoint. Age-related changes in the regulation of cytochrome P450 (CYP) genes, encoding the most common drugmetabolizing enzymes, might be responsible of the observed age-associated drift towards ADRs and TFs. In this review article, a complete impression of the CYP pharmacogenetics and epigenetics is reported in the context of increasing age, in which epigenetic CYP-gene regulation might change. Physiological age-related changes in DNA-methylation, the main epigenetic mechanisms regulating gene expression in humans, results in a physiological decrease in CYP gene expression with advancing age. This may be one of the physiological changes that, together with an increased drug use, contributed to raise the prevalence of severe responder phenotypes in older age.

\section{Introduction}

The worldwide trend towards an older mean age strongly increases the number of patients attending geriatric wards, and creates new challenges in understanding unwanted outcomes in drug treatments. Because to an increased comorbidity, drug use rises with age, growing the prevalence of adverse drug reactions (ADRs) and therapeutic failures (TFs), the two counterposed faces of a disturbed drug metabolism. ${ }^{1}$ ADRs are worldwide primary causes of morbidity and mortality in older people, ${ }^{2,3}$ being responsible of $6.2-6.7 \%$ of all hospitalizations, and causing $0.15-0.3 \%$ of death among all U.S. and in Western countries Hospital admissions. ${ }^{4,5}$ Recent estimate of the US Agency for Healthcare Research and Quality
$(\mathrm{AHRQ})^{6}$ indicates that about 770,000 people/year are injured or die in clinic from ADRs, that overall may cost up to US $\$ 5.6$ million per hospital. These estimates did not include ADR-caused admissions and National hospital expenses to treat patients who suffer ADRs during hospitalization, that are estimated between $\$ 1.56$ and $\$ 5.6$ US billion extra costs annually. ${ }^{6}$ Conversely to ADRs, since TFs are not responsible of drug-associated mortality, less epidemiological data are available, ${ }^{7}$ and despite responsible of $18 \%$ of all hospitalizations ${ }^{8}$ the overall cost of TF-caused hospital admissions is still unknown.

\section{Materials and Methods}

\section{Epigenetics and age}

The early concept of molecular biology reporting that DNA is the only source of genetic information, with information flowing from DNA to RNA to proteins ${ }^{9}$ is still valid. However, the inter-individual phenotypic variability observed in drug responses cannot be fully explained by known variability in the genes encoding drug metabolizing enzymes (DMEs), transporters (DTs), and receptors (DRs). Thus, an additional source of variation is needed. Studies on monozygotic twins have demonstrated that this is accomplished by epigenetic modifications..$^{10,11}$ Indeed, the concept that interindividual epigenetic differences might be responsible of interindividual differences in drug metabolism has been recently proposed. ${ }^{12,13}$ Current knowledge stated that epigenetic act through two main mechanisms: methylation, at both DNA and protein levels (mainly histones), and microRNA (miRNA) interference, all involved in the regulation of gene expression. ${ }^{14,15}$ Among these mechanisms, DNA methylation is probably the best conserved form of gene regulation through evolution. ${ }^{16,17}$ Although methylation exists as a relatively stable and inheritable modification, it is widely accepted that is the result of long/short-term dynamic methylation/demethylation equilibrium continuing throughout lifespan, but also changing day-by-day in response to environmental stimuli ${ }^{18,19}$ In particular, DNA methylation is the well known mechanism by which gene silencing is obtained. ${ }^{20}$ DNA methylation is catalyzed by the DNA methyltransferase enzymes (DNMTs). In humans, DNMT-I is known as the maintenance methylase,${ }^{21}$ whereas DNMT-3a and DNMT-3b are de novo methylases.22,23 The ten eleven translocation family enzymes, instead, are the enzymes responsible of demethylation process. ${ }^{24}$

The genetic information encoded in DNA did not change with age. Conversely, it is well documented that methylation patterns ${ }^{25}$ chan-
Correspondence: Davide Seripa, Geriatric Unit and Gerontology-Geriatrics Research Laboratory, Department of Medical Sciences, I.R.C.C.S. Casa Sollievo della Sofferenza, Viale Cappuccini 1, 71013 San Giovanni Rotondo (FG), Italy.

E-mail: dseripa@operapadrepio.it

Key words: Adverse drug reactions; therapeutic failures; cytochrome P450; epigenetics; DNA methylation; geriatrics.

Acknowledgements: this work was supported by Ministero della Salute, IRCCS Research Program, Ricerca Corrente 2015-2017, Linea n. 2 Malattie complesse e terapie innovative and by the $5 \times 1000$ voluntary contribution.

Received for publication: 28 July 2015. Revision received: 5 October 2015 .

Accepted for publication: 12 0ctober 2015.

This work is licensed under a Creative Commons Attribution-NonCommercial 4.0 International License (CC BY-NC 4.0).

(C) Copyright D. Seripa et al., 2015

Licensee PAGEPress, Italy

Geriatric Care 2015; 1:5461

doi:10.4081/gc.2015.5461

ge with age..$^{26,27}$ Overall, a physiological process towards a global genome hypomethylation ${ }^{28,29}$ and a specific hypermethylation with age $\mathrm{e}^{30,31}$ is observed. Accordingly, in the context of advancing age, in which a general hypermethylation of the promoter regions is observed, all genes regulated by DNA methylation tended to reduced their expression, including DMEs, DTs and DRs and other genes involved in drug metabolism and distribution. Whereas, it has been largely demonstrated that DNA methylation changes in human cells and tissues with age, data regarding the other two epigenetic mechanisms, histones modification by methylation and miRNA interference, are less clear. Thus, DNA methylation may be the valid mechanisms to explain age-related differences in the overall interindividual variation observed in drug response throughout age-related differences in the regulation of DMEs, DTs and DRs expression.

\section{Genetics, epigenetics and drug response}

The perception that inherited factors might contribute to interindividual differences in drug response was not a recent one,$^{32,33}$ and currently, this concept is widely accepted ${ }^{34}$ and validated. ${ }^{35,36}$ In this context, inherited variants in DME encoding genes, mainly cytochromes P450 (CYPs), ${ }^{37}$ may play a major role. ${ }^{38,39}$ Clearly, this great gene diversity results into a high variability in the activity of the encoded enzymes. Potentially, in this system, the cataly- 
tic activity of each enzyme ${ }^{40}$ differed from each other. ${ }^{41,42}$ However, modern pharmacology did not completely take advantage from this system since more than $90-95 \%$ of the CYP reactions with drugs are catalyzed only by five (CYP1A2, CYP2C9, CYP2C19, CYP2D6, and CYP3A4) of the 44 CYP subfamilies (11.36\%), with the latter enzyme (CYP3A4) accounting for approximately $50 \%$ of the total CYP reactions. ${ }^{43}$ The concept of an epigenetic regulation of CYPs ${ }^{44,45}$ is not recent. ${ }^{46,47}$ However, DNA methylation appeared as the main epigenetic mechanism to regulate several CYP enzymes ${ }^{48,49}$ in the CYP gene-families 1 (CYP1), ${ }^{50} 2$ (CYP2), 3 (CYP3), the most important families in the adult liver contributing to the metabolism of about $70 \%$ of clinically used drugs ${ }^{41}$ and 4 (CYP24). Accordingly, inherited variants in CYP genes, as well as inherited changes in the epigenetic regulation of CYP gene expression, might well play the role of those genetic factors moving the drug response to far from the better.

The advent of the human genome project have lead to the identification of a number of genes encoding important drug transporters and receptors and considerable progress has been made in understanding their molecular characteristics. In fact, since their roles in drugs and metabolites transport inward and outward of the cells, in the recent years their pharmacogenetics has been well studied. Now, it becomes clear that some transporters are responsible for drug transport and effect in various tissues, and may be key determinants of the pharmacokinetic characteristics of a drug, i.e., intestinal absorption, tissue distribution and elimination. ${ }^{51}$ However, no clear data are available regarding the epigenetic regulation of these genes, ${ }^{52}$ thus suggesting a minor role in age-related changes in the response to drug treatments. It must be noted that a number of gene superfamilies encoding drug transporters/receptors has been early identified. However, none of these families showed a polymorphic level comparable with those observed in the CYP gene superfamily, thus still remains the point of intervention for pharmacogenetics, with drug transporters and receptors playing a minor role.

\section{Translating pharmacogenetics in clinical practice}

Several recent papers confirmed the usefulness of pharmacogenetics in the clinical practice, really making pharmacogenetics crosssectional to several disciplines.

For example, it has been recently demonstrated that CYP2C9 genotyping may be useful to identify subgroups of patients who potentially are at increased risk of gastroduodenal bleeding when treated with CYP2C9-metabolized non-steroidal anti-inflammatory drugs..$^{53} \mathrm{~A}$ more wide role may be identified for CYP2D6, ${ }^{54}$ genotyping that may influence: i) the clinical efficacy of donepezil, an acetyl cholinesterase inhibitor commonly used in the treatment of mild-to-moderate Alzheimer's disease (AD), being useful in clinical practice in identifying patient subgroups with AD who have different clinical response to donepezil treatment; ${ }^{55,56}$ and ii) levels of sedation and analgesia in postoperative pain treatment. ${ }^{57}$ Accordingly, the cross-sectional role of CYP2D6 genotyping in the identification of responder/non-responder patients to CYP2D6-metabolized drug has been well documented. ${ }^{54}$

It is noteworthy that all these reported clinical applications may be investigated for their role in a geriatric setting by the simple analysis of CYP gene epigenetic regulation by methylation by using commercially available kits.

\section{Discussion and Conclusions}

The better response to a given drug lies in the midpoint of a continuum of phenotypes in which ADRs and TFs are simply the severe counterposed manifestations. The genetics variability underlying the CYP enzymatic system is the basis of this range of phenotypes on which a number of environmental and physiological factors act to modeling the final phenotype observed in clinical practice. Physiological age-related changes in DNAmethylation, the main epigenetic mechanism regulating gene expression in humans, resulted in a progressive genome-wide demethylation and increased promoter regions hypermethylation through the genome, resulting in a progressive physiological gene silencing. It is also clear that in the context of aging, all genes regulated by DNA methylation tended to be reduced in their expression, including CYP and other genes encoding proteins involved in drug metabolism and distribution. This may be one of the physiological changes that, together with an increased drug use, contributed to raised the prevalence of severe responder phenotypes in the geriatric settings.

It is clear that an increased comorbidity is responsible of an increasing number of concomitant therapies, but not sufficient to justify the increased prevalence of ADRs and TFs observed in geriatric practice. Accordingly, CYP genetic variability, the basis of the interindividual difference in the response to drugs, did not change during lifespan. Thus, to justify the pharmacological condition of a geriatric setting, longitudinal factors changing with age possibly influencing CYP genetics must be identified. Accordingly, the introduction of a physiological mechanism regulating CYP gene expression according to age fill this gap and explained as CYP genetics may be dynamic, assuming a longitudinal role in influencing the prevalence of severe responder phenotypes.
Epigenetic processes regulating gene expression, in particular DNA methylation, well plays this role. DNA methylation is the epigenetic mechanism of gene regulation most conserved by evolution, and the main mechanism by which gene silencing is obtained. It is also well demonstrated that DNA methylation is the dynamic process by which environmental and physiological process might influence gene expression. This means that a progressive reduction of CYP gene expression is expected with advancing age, resulting in unbalanced drug metabolism and a different prevalence of responder phenotypes in a geriatric setting. If this is true, then really pharmacogenetics may be longitudinal, suitable to evaluate longitudinal changes in drug metabolism according to increasing age, thus permitting the application of pharmacogenetics in a geriatric setting. Basically, we did not need further research or knowledge. Up to date, we have all acknowledges needed to translate pharmacogenetics in a geriatric setting. The status of what we know and what we need to know is the base for the clinical applications of pharmacogenetics, in which personalized drug treatments constituted the main aim, in particular in patients attending a geriatric ward.

\section{References}

1. Seripa D, Panza F, Daragjati J, et al. Measuring pharmacogenetics in special groups: geriatrics. Expert Opin Drug Metab Toxicol 2015;11:1073-88.

2. Franceschi M, Scarcelli C, Niro V, et al. Prevalence, clinical features and avoidability of adverse drug reactions as cause of admission to a geriatric unit: a prospective study of 1756 patients. Drug Saf 2008; 31:545-56.

3. Petrovic M, van der Cammen T, Onder G. Adverse drug reactions in older people: detection and prevention. Drugs Aging 2012;29:453-62.

4. Moore TJ, Cohen MR, Furberg CD. Serious adverse drug events reported to the Food and Drug Administration, 1998-2005. Arch Intern Med 2007;167:1752-9.

5. Miguel A, Azevedo LF, Araújo M, et al. Frequency of adverse drug reactions in hospitalized patients: a systematic review and meta-analysis. Pharmacoepidemiol Drug Saf 2012;21:1139-54.

6. AHRQ - Agency for Healthcare Research and Quality, Advancing Excellence in Health Care. Reducing and preventing adverse drug events to decrease hospital costs. Research in action. Available from: http://archive.ahrq.gov/research/findings/f actsheets/errors-safety/aderia/ade.html

7. Marcum ZA, Pugh MJ, Amuan ME, et al. 
Prevalence of potentially preventable unplanned hospitalizations caused by therapeutic failures and adverse drug withdrawal events among older veterans. J Gerontol A Biol Sci Med Sci 2012;67:867-74.

8. Patel RS, Marcum ZA, Peron EP, et al. Prevalence of and factors associated with therapeutic failure-related hospitalizations in the elderly. Consult Pharm 2014; 29:376-86.

9. Crick F. Central dogma of molecular biology. Nature 1970;227:561-3.

10. Petronis A, Gottesman II, Kan P, et al. Monozygotic twins exhibit numerous epigenetic differences: clues to twin discordance? Schizophr Bull 2003;29:169-78.

11. Fraga MF, Ballestar E, Paz MF, et al. Epigenetic differences arise during the lifetime of monozygotic twins. Proc Natl Acad Sci U S A 2005;102:10604-9.

12. Baer-Dubowska W, Majchrzak-Celinska M, Cichocki M. Pharmacoepigenetics: a new approach to predicting individual drug responses and targeting new drugs. Pharmacological Rep 2011;63:293-304.

13. Kacevska M, Ivanov M, IngelmanSundberg M. Perspectives on epigenetics and its relevance to adverse drug reactions. Clin Pharmacol Ther 2011;89: 902-7.

14. Berger SL, Kouzarides T, Shiekhattar R, Shilatifard A. An operational definition of epigenetics. Genes Dev 2009;23:781-3.

15. Mukherjee K, Twyman RM, Vilcinskas A. Insects as models to study the epigenetic basis of disease. Prog Biophys Mol Biol 2015 [Epub ahead of print].

16. Casadesús J, Low D. Epigenetic gene regulation in the bacterial world. Microbiol Mol Biol Rev 2006;70:830-56.

17. Zemach A, McDaniel IE, Silva P, et al. Genome-wide evolutionary analysis of eukaryotic DNA methylation. Science 2010; 328:916-9.

18. Klose RJ, Bird AP. Genomic DNA methylation: the mark and its mediators. Trends Biochem Sci 2006;31:89-97.

19. Reddington JP, Pennings S, Meehan RR. Non-canonical functions of the DNA methylome in gene regulation. Biochem $\mathrm{J}$ 2013;451:13-23.

20. Li E, Zhang Y. DNA methylation in mammals. Cold Spring Harb Perspect Biol 2014; 6:a019133.

21. Okano M, Xie S, Li E. Cloning and characterization of a family of novel mammalian DNA (cytosine-5) methyltransferases. Nat Genet 1998;19:219-20.

22. Xie S, Wang Z, Okano M, et al. Cloning, expression and chromosome locations of the human DNMT3 gene family. Gene 1999;236:87-95.

23. Hermann A, Gowher H, Jeltsch A. Biochemistry and biology of mammalian
DNA methyltransferases. Cell Mol Life Sci 2004;61:2571-87.

24. Kohli RM, Zhang Y. TET enzymes, TDG and the dynamics of DNA demethylation. Nature 2013;502:472-9.

25. Issa JP. Aging and epigenetic drift: a vicious cycle. J Clin Invest 2014;124:24-9.

26. Johnson AA, Akman K, Calimport SR, et al. The role of DNA methylation in aging, rejuvenation, and age-related disease. Rejuvenation Res 2012;15:483-94.

27. Ben-Avraham D, Muzumdar RH, Atzmon G. Epigenetic genome-wide association methylation in aging and longevity. Epigenomics 2012;4:503-9.

28. Bjornsson HT, Sigurdsson MI, Fallin MD, et al. Intra-individual change over time in DNA methylation with familial clustering. JAMA 2008;299:2877-83.

29. Bollati V, Schwartz J, Wright R, et al. Decline in genomic DNA methylation through aging in a cohort of elderly subjects. Mech Ageing Dev 2009;130:234-9.

30. Liu L, van Groen T, Kadish I, et al. Insufficient DNA methylation affects healthy aging and promotes age-related health problems. Clin Epigenetics 2011;2: 349-60.

31. Heyn H, Li N, Ferreira HJ, et al. Distinct DNA methylomes of newborns and centenarians. Proc Natl Acad Sci U S A 2012; 109:10522-7.

32. Meyer UA. Pharmacogenetics and adverse drug reactions. Lancet 2000;356:1667-71.

33. Pirmohamed M, Park BK. Genetic susceptibility to adverse drug reactions. Trends Pharmacol Sci 2001;22:298-305.

34. Güzey C, Spigset 0. Genotyping as a tool to predict adverse drug reactions. Curr Top Med Chem 2004;4:1411-21.

35. Wilke RA, Lin DW, Roden DM, et al. Identifying genetic risk factors for serious adverse drug reactions: current progress and challenges. Nat Rev Drug Discov 2007; 6:904-16

36. Ingelman-Sundberg M. Pharmacogenomic biomarkers for prediction of severe adverse drug reactions. N Engl J Med 2008;358: 637-9.

37. Lynch T, Price A. The effect of cytochrome P450 metabolism on drug response, interactions, and adverse effects. Am Fam Physician 2007;76:391-6.

38. Seripa D, Pilotto A, Panza F, et al. Pharmacogenetics of cytochrome P450 (CYP) in the elderly. Ageing Res Rev 2010; 9:457-74.

39. Johansson I, Ingelman-Sundberg M. Genetic polymorphism and toxicology with emphasis on cytochrome p450. Toxicol Sci 2011;120:1-13.

40. Daly AK, Cholerton S, Gregory W, Idle JR. Metabolic polymorphisms. Pharmacol Ther 1993;57:129-60.
41. Ingelman-Sundberg M, Oscarson M, McLellan RA. Polymorphic human cytochrome P450 enzymes: an opportunity for individualized drug treatment. Trends Pharmacol Sci 1999;20:342-9.

42. Evans WE, Relling MV. Pharmacogenomics: translating functional genomics into rational therapeutics. Science 1999;286:487-91.

43. Gardiner SJ, Begg EJ. Pharmacogenetics, drug-metabolizing enzymes, and clinical practice. Pharmacol Rev 2006;58:521-90.

44. Ingelman-Sundberg M, Sim SC, Gomez A, et al. Influence of cytochrome $\mathrm{P} 450$ polymorphisms on drug therapies: pharmacogenetic, pharmacoepigenetic and clinical aspects. Pharmacol Ther 2007;116: 496-526.

45. Hirota T, Takane H, Higuchi $\mathrm{S}$, et al. Epigenetic regulation of genes encoding drug-metabolizing enzymes and transporters; DNA methylation and other mechanisms. Curr Drug Metab 2008;9:34-8.

46. Gomez A, Ingelman-Sundberg M. Pharmacoepigenetics: its role in interindividual differences in drug response. Clin Pharmacol Ther 2009;85:426-30.

47. Gomez A, Ingelman-Sundberg M. Epigenetic and microRNA-dependent control of cytochrome P450 expression: a gap between DNA and protein. Pharma-cogenomics 2009;10:1067-76.

48. Tang J, Xiong Y, Zhou HH, et al. DNA methylation and personalized medicine. $\mathrm{J}$ Clin Pharm Ther 2014;39:621-7.

49. Zanger UM, Klein K, Thomas M, et al. Genetics, epigenetics, and regulation of drug-metabolizing cytochrome p450 enzymes. Clin Pharmacol Ther 2014;95:258-61.

50. Naselli F, Catanzaro I, Bellavia D, et al. Role and importance of polymorphisms with respect to DNA methylation for the expression of CYP2E1 enzyme. Gene 2014; 536:29-39.

51. Pilotto A, Panza F, Seripa D. Pharmacogenetics in geriatric medicine: challenges and opportunities for clinical practice. Curr Drug Metab 2011;12:621-34.

52. Kacevska M, Ivanov M, Ingelman-Sundberg M. Epigenetic-dependent regulation of drug transport and metabolism: an update. Pharmacogenomics 2012;13: 1373-85.

53. Pilotto A, Seripa D, Franceschi M, et al. Genetic susceptibility to nonsteroidal antiinflammatory drug-related gastroduodenal bleeding: role of cytochrome P450 2C9 polymorphisms. Gastroenterology 2007; 133:465-71.

54. Savino M, Seripa D, Gallo AP, et al. Effectiveness of a high-throughput genetic analysis in the identification of responders/non-responders to CYP2D6-metabolized drugs. Clin Lab 2011;57:887-93.

55. Pilotto A, Franceschi M, D’Onofrio G, et al. Effect of a CYP2D6 polymorphism on the 
efficacy of donepezil in patients with Alzheimer disease. Neurology 2009;73: 761-7.

56. Seripa D, Bizzarro A, Pilotto A, et al. Role of cytochrome P4502D6 functional polymorphisms in the efficacy of donepezil in patients with Alzheimer's disease. Pharmacogenet Genomics 2011;21:225-30.

57. Seripa D, Latina P, Fontana A, et al. Role of CYP2D6 polymorphisms in the outcome of postoperative pain treatment. Pain Med 2015;16:2012-2023. 